\title{
Pepsinogen synthesis and secretion in isolated gastric glands
}

\author{
J DÉFIZE, G PALS, RR FRANTS, BD WESTERVELD, SGM MEUWISSEN, AW ERKISSON
}

From the Institute of Human Genetics and Department of Gastroenterology, Faculty of Medicine, Free University, PO Box 7161, 1007 MC Amsterdam, The Netherlands.

SUMMARY De novo synthesis of pepsinogen was shown in isolated rabbit and human gastric glands after incubation of the glands in a ${ }^{14} \mathrm{C}$ labelled amino acid enriched minimum Eagles medium. At regular intervals, glands and medium were separated and analysed by polyacrylamide gel electrophoresis. Newly synthesised pepsinogen was shown by autoradiography. Incorporation of ${ }^{14} \mathrm{C}$ labelled amino acids was detected after only $30 \mathrm{~min}$ of culture and increased almost linearly in time for $4 \mathrm{~h}$. By comparing the incorporation of label into total protein and into pepsinogen, it was concluded that pepsinogen formed $70-90 \%$ of the newly synthesised protein.

Cimetidine, at a concentration of $160 \mu \mathrm{g} / \mathrm{ml}$, strongly inhibited the synthesis of pepsinogen. Spontaneous secretion of pepsinogen into the medium was very low and relatively constant. Dibutyryl cyclic AMP considerably stimulated the secretion of pepsinogen into the medium. Histamine and pentagastrin did not influence the release of pepsinogen.

These results show that isolated gastric glands are capable of synthesis and secretion of pepsinogen and that both can be selectively stimulated and inhibited.

Pepsinogen is synthesised in the gastric mucosa by the chief and neck cells of the glandular ducts and is secreted into the lumen of the gastric gland. ${ }^{1-3}$ Human pepsinogen can be separated on polyacrylamide gel electrophoresis into seven isozymogens, consisting of two immunochemically distinct groups: pepsinogen A (formerly pepsinogen I, fractions 1-5) and pepsinogen $C$ (formerly pepsinogen II, fractions 6 and 7). In contrast to pepsinogen $C$, pepsinogen $A$ is secreted in the urine and shows considerable interindividual heterogeneity. Several genetic models have been proposed to explain the inheritance of urinary pepsinogen $A .^{4-6}$

We have postulated a new multigene model for pepsinogen $A$, in which the main fractions, 3,4 , and 5 are each coded for by a specific gene, B, C, and D respectively.' Furthermore, we recently described an association between distinct electrophoretic pepsinogen A patterns in biopsy samples of gastric mucosa and (pre)malignancy of the stomach. ${ }^{8}$ These findings suggest a predisposition of some genetic pepsinogen A types to malignancy of the stomach. There were, however, considerable intraindividual differences between the pepsinogen $\mathrm{A}$ isozymogen

Accepted for publication 24 January 1984 patterns in stomach tissue and urine in about $10 \%$ of the patients studied. This discrepancy makes it questionable to use urinary pepsinogen analyses for the prediction of the gastric mucosa pepsinogen A patterns for clinical purposes.

There are several explanations for this discrepancy:

1 Differential secretion or reabsorption of the pepsinogen $\mathrm{A}$ isozymogens by the kidney.

2 Differential secretion by the zymogen cell.

3 Interconversion of the isozymogens.

4 Different synthesis regulation mechanisms for the separate isozymogens.

The secretion of pepsinogen has been studied extensively in vivo and in vitro. ${ }^{1-3910} \mathrm{Koelz}$ et al ${ }^{9}$ studied cholinergic and $\beta$-adrenergic stimulated pepsinogen release in isolated rabbit gastric glands and their results indicated that pepsinogen release is regulated in part by separate cholinergic and $\beta$-adrenergic mechanisms and that cyclic AMP plays a role in this regulation.

Few studies have been performed on pepsinogen synthesis either in vivo or in vitro. In 1976 Sutton and Donaldson reported the in vitro synthesis of pepsinogen in cultured rabbit gastric mucosa tissue. ${ }^{10}$ In these investigations, however, the secretion or synthesis of total pepsinogen and not that of the 
separate isozymogens was studied. To investigate the inter-relation between the pepsinogen $A$ fractions - that is, the effect of genetics, posttranslational modifications, and differential secretion-a reproducible technique for studying de novo pepsinogen synthesis and secretion of this newly synthesised pepsinogen in vitro was needed. Using the tissue culture technique of Browning and Trier, "we have shown that whole biopsy samples of human gastric mucosa taken at routine gastroendoscopy are capable of pepsinogen synthesis (Pals and Défize, unpublished observations). This technique showed considerable intra- and interbiopsy variation in pepsinogen synthesis, which made it difficult to evaluate pulse and dose response studies. Furthermore, it was impossible to take multiple identical samples of cells and medium at different times. We report here the synthesis and secretion of pepsinogen by isolated rabbit and human gastric glands.

\section{Material and methods}

\section{ISOLATION OF GASTRIC GLANDS}

Isolation was done essentially according to the method of Berglindh et al..$^{12}$ Briefly, the stomach of an anaesthetised rabbit was perfused with saline under high pressure through the aorta. The stomach was removed, and the mucosa stripped, minced into small pieces, and transferred to a collagenase solution (1 $\mathrm{mg} / \mathrm{ml}$, type I, Sigma) After $90 \mathrm{~min}$ incubation at $37^{\circ} \mathrm{C}$ the separated glands were repeatedly washed to remove free cells, and then resuspended in culture medium. Human biopsy samples, obtained by fibre endoscopy from patients, were treated with collagenase for $120 \mathrm{~min}$. Viability of the glands was confirmed by the trypan blue exclusion test. As culture medium, amino acid free minimum essential medium was used, prepared from a minimum essential medium select amine kit (Gibco RPM1 1640). To this was added: penicillin (100 U/ml); streptomycin $(100 \mu \mathrm{g} / \mathrm{ml})$; insulin (porcine; $0.6 \mathrm{U} / \mathrm{ml}$ ) and $10 \%$ fetal calf serum. Culture was performed in Eppendorf no 403 tubes in a rotating waterbath at $37^{\circ} \mathrm{C}$. Labelling was done by adding $2.0 \mu \mathrm{Ci}^{14} \mathrm{C}$ amino acid mixture (Amersham CFB $104,250 \mu \mathrm{Ci} / \mathrm{ml}$ ) to a number of tubes containing $200 \mu \mathrm{l}$ gland suspension. Reagents added were of the highest purity available: dibutyryl cyclic AMP, carbachol, and histamine were obtained from Sigma, St Louis, USA; pentagastrin (peptavlon) from ICI, England; cimetidine was a gift from Smith, Kline and French, Hertfordshire, England.

In pulse chase experiments, glands were pulse labelled for $30 \mathrm{~min}$, washed once in unlabelled culture medium, resuspended again in unlabelled cul- ture medium, and cultured for additional different time intervals. Duplicate tubes were removed at regular intervals, and glands and medium were separated by centrifugation. Glands were resuspended in $100 \mu \mathrm{l} 0.1 \mathrm{M}$ phosphate buffer, $\mathrm{pH} 8$, and sonified; $50 \mu \mathrm{l}$ aliquots of medium and gland homogenates were subjected to polyacrylamide gel electrophoresis, according to Pals and Défize..$^{13} \mathrm{Gels}$ were stained for pepsinogen activity or autoradiographed. Before autoradiography, gels were stained for protein, using a $0.1 \%$ Coomassie brilliant blue G250 solution (Biorad) in $12.5 \%$ trichloroacetic acid. Gels were then incubated in $\mathrm{En}^{3}$ hance (New England Nuclear, Boston, USA) for $1 \mathrm{~h}$ and, after washing in water, dried and put on Kodak Safety film AR or RX-1 on an intensifying screen (SP 02810511 ) and stored in the dark at $-70^{\circ} \mathrm{C}$ for one week. After autoradiography, the pepsinogen isozymogen pattern was cut out of the gel, put in vials, and ${ }^{14} \mathrm{C}$ incorporation in pepsinogen was measured in a liquid scintillation counter. Total incorporation of label into protein was determined by trichloroacetic acid precipitation. Assessment of total protein content of the glands was done by the Biorad protein assay. Pepsinogen synthesis was expressed as ${ }^{14} \mathrm{C}$ incorporation per milligram total protein content of the incubated glands. Secretion of pepsinogen was expressed as percentage of newly synthesised pepsinogen (intracellular and secreted) per incubation.

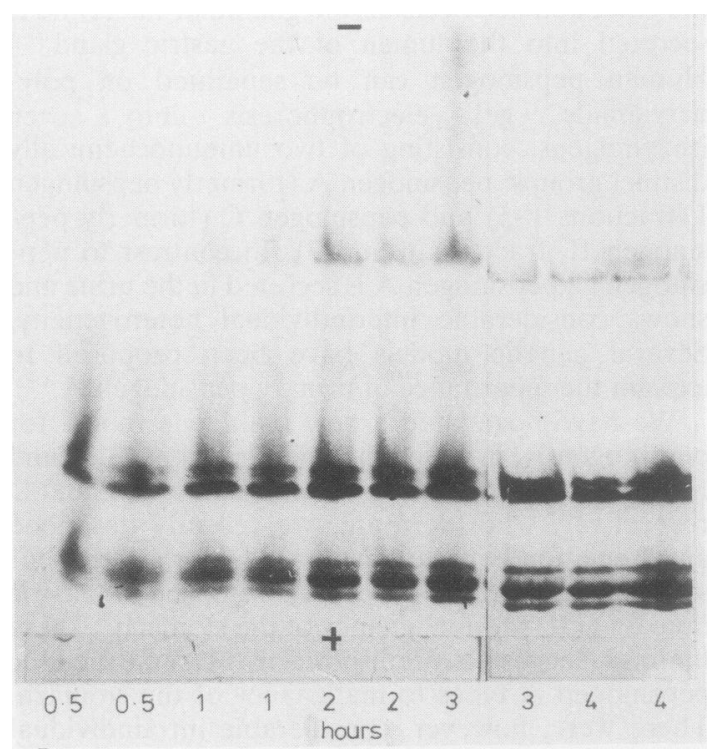

Fig. 1 Autoradiograph of cultured rabbit gastric glands after polyacrylamide gel electrophoresis Glands were cultured in the presence of $2 \mu \mathrm{Ci}{ }^{14} \mathrm{C}$ amino acids for different time intervals. 


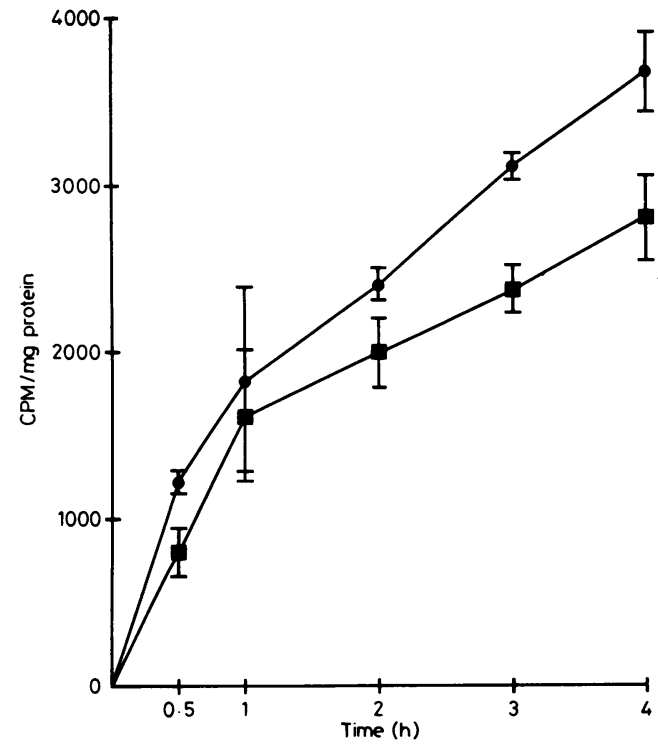

Fig. 2 Time course of synthesis by isolated rabbit gastric glands. - Incorporation into total protein/mg total protein content of the glands. - Incorporation into pepsinogen/mg total protein content of the glands. Results shown are derived from duplicate values of one experiment. This experiment is representative of three others. $C P M=$ counts per minute.

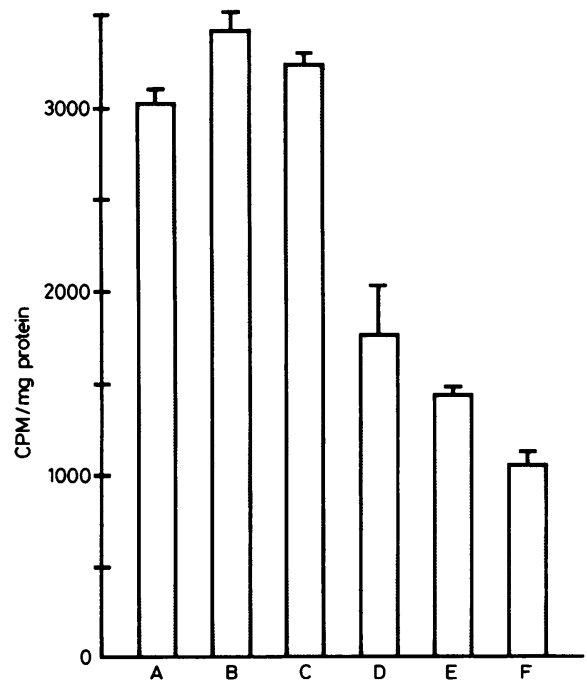

Fig. 3 Synthesis of pepsinogen by rabbit glands in the presence of various compounds, Glands were cultured for 4 h. (A) control; $(B)+1$ mM dibutyryl cyclic AMP; $(C)+1$ $m M$ sodium thiocyanide; $(D)+40 \mu g$ cimetidine; $(E)+80$ $\mu g$ cimetidine; $(F)+160 \mu g$ cimetidine. Synthesis was expressed as CPM/mg total protein content of the glands. Results shown are derived from duplicate values of one experiment which is representative of three others. $C P M=$ counts per minute.

\section{Results}

Isolated glands were cultured for a maximum of $4 \mathrm{~h}$. At intervals, samples were taken in duplicate and analysed for pepsinogen synthesis. Fig. 1 shows an autoradiograph of cultured rabbit glands after electrophoresis. Incorporation of label was detectable already after only 30 minutes. Protein and pepsinogen activity staining of the same samples showed that incorporation of label was predominantly into pepsinogen. This was confirmed by comparing label incorporation in total protein and in pepsinogen as a function of time: $70-90 \%$ of the label was incorporated into pepsinogen (Fig. 2). When the glands were incubated in the presence of cimetidine (40$160 \mu \mathrm{g} / \mathrm{ml} ; 0 \cdot 15-0.6 \mathrm{mM}$ ) a strong dose dependent inhibition of the pepsinogen synthesis was observed, while pentagastrin or histamine (at a concentration of $1 \mathrm{mM}$ ) showed no effect (Fig. 3).

\section{STIMULATION OF PEPSINOGEN RELEASE}

Fig. 4 shows an autoradiograph of the secreted pepsinogen. After $2 \mathrm{~h}$ secretion of the newly synthesised pepsinogen was observed. Basal pepsinogen secretion was very low. An almost two fold increase of pepsinogen release compared with controls was

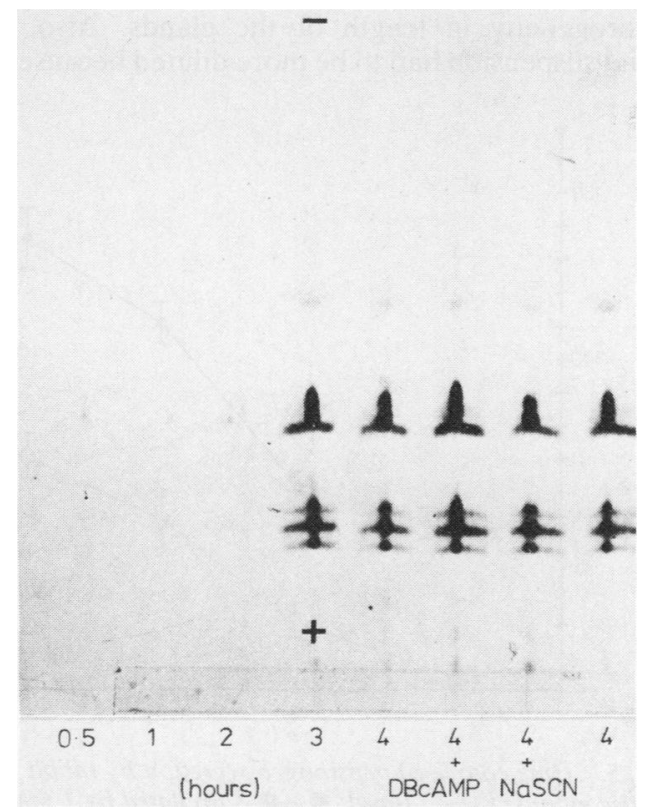

Fig. 4 Autoradiograph of secreted pepsinogen by rabbit gastric glands after polyacrylamide gel electrophoresis of the culture medium. Staining for protein of the same gel before autoradiography shows secretion of unlabelled pepsinogen at $0 \cdot 5,1$ and 2 h. DBc $A M P=$ dibutyryl cyclic $A M P$. 
found when the glands were cultured in the presence of $1 \mathrm{mM}$ dibutyryl cyclic AMP (Fig. 5). As dibutyryl cyclic AMP also stimulates acid secretion by the parietal cells, the pepsinogen secretion increase could be caused by increased acid output. Blocking the acid secretion by cimetidine or neutralising the secreted acid with $1 \mathrm{mM}$ sodium thiocyanide, however, did not alter the stimulating effect of dibutyryl cyclic AMP on the pepsinogen release. We therefore conclude that the effect of dibutyryl cyclic AMP is a direct one and is not mediated by the increased acid output of the parietal cell (Fig. 6). Cholinergic stimulation by culturing the glands in the presence of $1 \mathrm{mM}$ carbachol resulted in a less pronounced increase in pepsinogen release compared with dibutyryl cyclic AMP.

The stimulation by both carbachol and dibutyryl cyclic AMP was abolished by the simultaneous addition of $1 \mathrm{mM}$ atropine. Glands cultured in the presence of cimetidine did not show an inhibition of pepsinogen release. Nor did we find a stimulating effect on the secretion by histamine or pentagastrin (Fig. 6).

\section{ISOLATED HUMAN GASTRIC GLANDS}

Isolation of human glands was more difficult than for rabbit glands. A longer collagenase digestion was needed (120 min), which also caused a considerable heterogeneity in length of the glands. Also, the gland suspension had to be more diluted because the

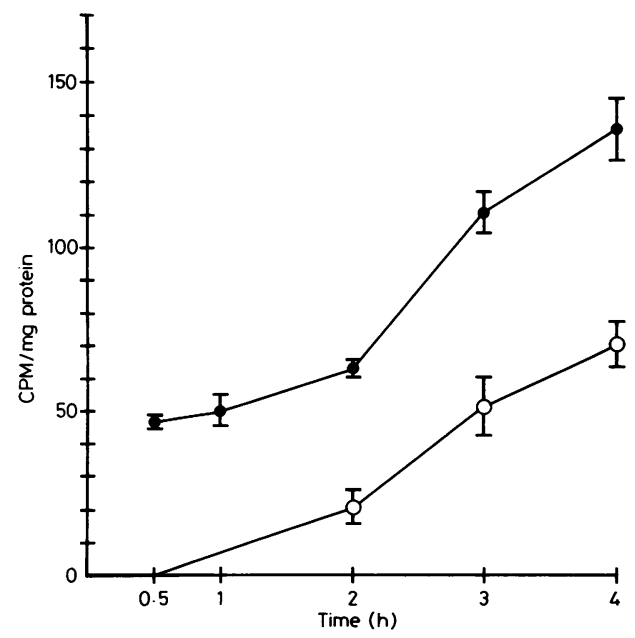

Fig. 5 Time course of pepsinogen secretion by rabbit gastric glands: $\bigcirc-\bigcirc$ Basal; $\longrightarrow$ Stimulated by $1 \mathrm{mM}$ dibutyryl cyclic AMP. Secretion at different times was expressed as the amount of incorporated label (CPM) in secreted pepsinogen/mg total protein content of the incubated glands. Values are means of three experiments \pm SD. $C P M=$ counts per minute.

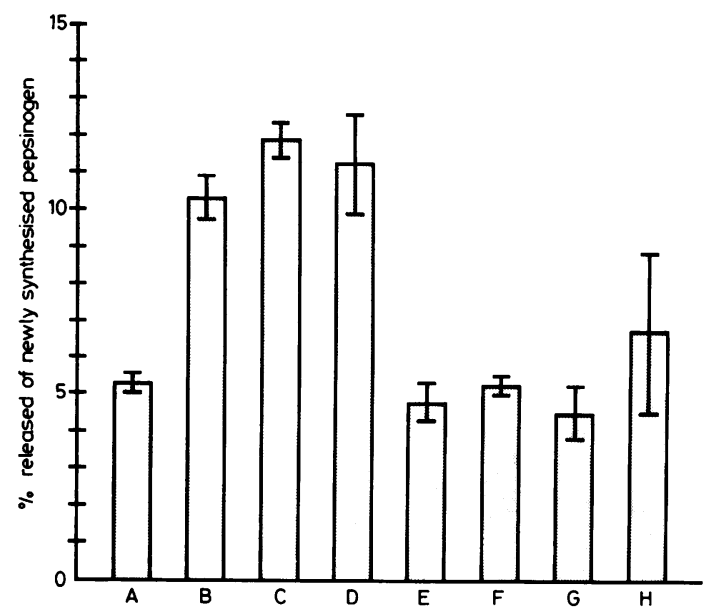

Fig. 6 Secretion of pepsinogen under infuence of various compounds. Rabbit glands were cultured for $4 \mathrm{~h}$ and secretion was expressed as percentage of newly synthesised pepsinogen per incubation. $(A)$ basal; $(B)+1 \mathrm{~mm}$ dibutyryl cyclic AMP; (C) $+1 \mathrm{mM}$ dibutyryl cyclic AMP $+1 \mathrm{mM}$ NaSCN; (D) $+1 \mathrm{mM}$ dibutyryl cyclic AMP $+160 \mu \mathrm{g} / \mathrm{ml}$ cimetidine; $(E)+1 \mathrm{mM} \mathrm{NaSCN} ;(F)+1 \mathrm{mM}$ pentagastrin; (G) $+1 \mathrm{mM}$ histamine; $(\mathrm{H})+160 \mu \mathrm{g} / \mathrm{ml}$ cimetidine. Values are means of three experiments $\pm S D$.

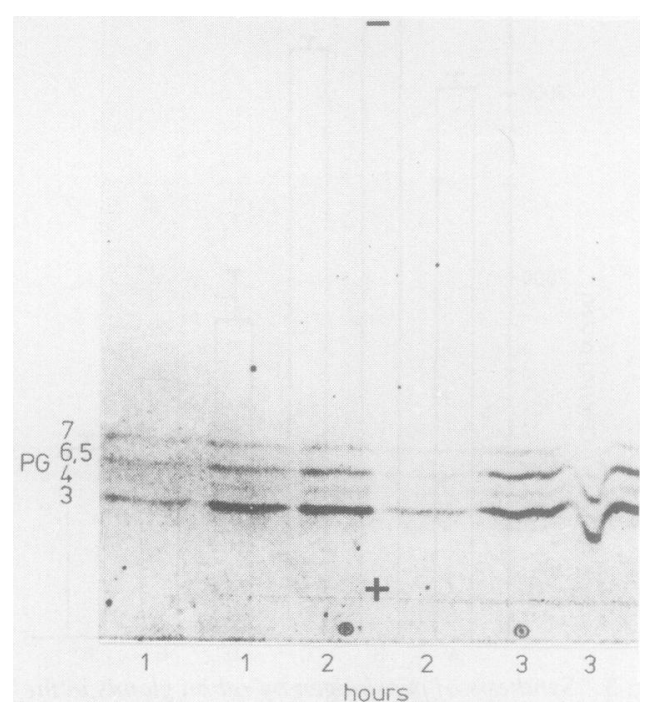

Fig. 7 Autoradiograph of cultured human glands after polyacrylamide gel electrophoresis showing synthesis of pepsinogen (PG) after different time intervals. Glands were cultured in the presence of ${ }^{14} \mathrm{C}$ labelled amino acids. Absence of other labelled proteins in the PG region of the gel was confirmed by electrophoresis of samples incubated with anti-pepsinogen- $A$ and anti-pepsinogen- $C$. 
glands aggregated very easily in concentrated suspensions. As in rabbit glands, incorporation of label was detectable after $30 \mathrm{~min}$, but it did not increase significantly in time. The absence of other labelled proteins in the pepsinogen region of the gel was determined by polyacrylamide gel electrophoresis of samples preincubated with anti-pepsinogen $A$ and anti-pepsinogen C. Label incorporation was again for $70-90 \%$ into pepsinogen and the action of several secretagogues was the same as described for the rabbit glands. Cimetidine again inhibited the synthesis of pepsinogen in a dose dependent manner.

No changes in time in the isozymogen pattern were noted; all the bands seemed to appear simultaneously, indicating that there is no common precusor for the isozymogens (Fig. 7). In pulse chase experiments we saw only an increase of pepsinogen A-2 at the expense of pepsinogen A-3, which confirmed the hypothesis that pepsinogen A-2 is a secondary product of pepsinogen A-3 (results not shown). No significant differences in the secreted and intracellular pepsinogen A pattern were found. In some cases the relative concentration of extracellular pepsinogen A-3 was slightly less than that of intracellular pepsinogen A-3.

\section{Discussion}

Berglindh et al $^{12}$ have shown that a preparation of isolated gastric glands is a good model system for studying gastric acid metabolism. Koelz et $a^{10}$ explored the potential of isolated glands for the study of pepsinogen secretion and found that isolated glands met the criteria for a good model system - that is, a high zymogen content and stable low rate of spontaneous secretion. Our study shows that isolated glands also provide a good system for studying pepsinogen synthesis on a cellular basis. The viability of the glands is confirmed by the incorporation of labelled amino acids into proteins. From the experiments with cimetidine, we conclude that the ability of cimetidine to lower the pepsinogen content in the stomach in vivo is probably due to inhibition of synthesis rather than secretion.

Little is known about the influence of several drugs on the secretion of pepsinogen. There is evidence for a separate $\beta$-adrenergic (mediated by cyclic AMP) and cholinergic stimulation, the cholinergic stimulation possibly being dependent on external calcium. ${ }^{9}$ This is in agreement with zymogen release in the pancreas ${ }^{14}$ and salivary glands. ${ }^{15}$

In contrast to the secretion stimulation capacity of histamine and pentagastrin in vivo, ${ }^{16}{ }^{17}$ we found no stimulation of pepsinogen secretion by these drugs in isolated glands. This is in agreement with other studies using the organ culture technique. ${ }^{318}$ Studies on isolated parietal cells have shown that the stimulatory effect of histamine on acid secretion is mediated by the adenylate cyclase-cyclic AMP system. ${ }^{90}$ It has been postulated that the $\beta$-adrenergic stimulation of pepsinogen release is also mediated by cyclic AMP. ${ }^{10}$ This is supported by our findings those of others ${ }^{91}$ that dibutyryl cyclic AMP stimulates pepsinogen secretion. We have established that this stimulation is a direct one and not mediated by an increased acid release of the parietal cell. The lack of stimulation by histamine (or its chemical derivative betazole hydrochloride) could be due to the rapid degradation of cyclic AMP by phosphodiesterase, as Ito et $a l^{21}$ found that simultaneous inhibition of phosphodiesterase by aminophylline considerably enhanced the stimulatory effect of betazole hydrochloride on pepsinogen release. In contrast, forskolin does stimulate the secretion of pepsinogen by isolated glands. ${ }^{22}$ This can be explained by the fact that forskolin is a much more potent stimulator of adenylate cyclase activity than histamine. Treatment with forskolin results in a 100 fold increase in tissue cyclic AMP concentration. $^{22}$ In how far the effects of several secretagogues on pepsinogen secretion and synthesis are a direct result of their action on the zymogen cell or are mediated by the parietal cell remains to be elucidated. Increasing the cyclic AMP content of the parietal cell will stimulate the acid output, and Johnson $^{23}$ showed, for example, that topical acidification of gastric mucosa with diluted hydrochloric acid resulted in a two fold increase of pepsinogen secretion. It would therefore be of great interest to investigate the potential of isolated zymogen cells for secretion and synthesis of pepsinogen.

The experiments with human gastric glands show that there is probably no common precursor for the pepsinogen A isozymogens. The secreted pepsinogen A pattern, except for minor differences between pepsinogen A-2 and pepsinogen A-3, was the same as the intracellular, excluding differential secretion in these cases. This study also shows that preparations of isolated gastric glands are indeed an excellent tool for studying synthesis and secretion of pepsinogen.

This study was supported by grant 31-41-41 from the Organization of Health Research GO/TNO and was facilitated by a study visit to AB Hässle, Mölndal, Sweden. We thank Smith, Kline and French, Hertfordshire, England, for their gift of cimetidine. Part of this work was presented as a paper at the first international workshop on pepsinogen and gastric disorders (Noordwijk, October 1983). 


\section{References}

${ }^{1}$ Dutt B, Magee DF. Pepsin secretion by Heidehain pouches in dogs. Am J Physiol 1972;223:480-3.

${ }^{2}$ Gibson R, Hirschowitz BI, Huchison G. Actions of methiamide, an $\mathrm{H} 2$ receptor antagonist on gastric $\mathrm{H}+$ and pepsin secretion in dogs. Gastroenterology 1977;67:93-9.

${ }^{3}$ Simpson L, Goldenberg D, Hirschowitz BI. Pepsinogen secretion by the frog oesophagus in vitro. Am J Physiol 1980;238:g79g48.

4 Samloff M, Townes PL. Pepsinogens: genetic polymorphism in man. Science 1970;168:144-5.

s Taggart RT, Yu PL, Karn RC, Conneally PM, Merrit AD. Genetic analysis of urinary pepsinogen isoproteins. Cytogenet Cell Genet 1978;22:335-40.

6 Korsnes L, Gedde-Dahl T. Genetics of pepsinogen I. Ann Hum Genet 1980;43:199-212.

' Frants RR, Pronk JC, Pals G, et al. Genetics of Pepsinogen: A new Hypothesis. Hum Genet 1984;65:385-90.

${ }^{8}$ Pals G, Défize J, Meuwissen SGM, et al. Pepsinogen I isoenzyme determination. Clinical significance? Gastroenterology 1981;80:1247.

${ }^{9}$ Koelz HR, Hersey SJ, Sachs G, Chew GS. Cholinergic and $\boldsymbol{\beta}$-adrenergic pepsinogen release by isolated rabbit glands. Gastroenterology 1981;80:1194-8.

${ }^{10}$ Sutton DR, Donaldson RM. Synthesis and secretion of protein and pepsinogen by rabbit gastric mucosa in organ culture. Gastroenterology 1975;69:166-74.

"Browning Th, Trier JS. Organ culture of mucosal biopsies of human small intestine. J Clin Invest 1975;48:1423-32.

${ }_{12}$ Berglindh T, Öbrink KJ. A method for preparing isolated glands from the rabbit gastric mucosa. Acta Physiol Scand 1976;96:150-9.

${ }^{13}$ Pals G, Défize J. Elektrophorese von Pepsinogen; mögliche klinische Anwendungen beim Magencarcinoom. In: Radola $B j$, ed. Elektrophorese forum. München: Technische Universität München, 1980:238-43.
${ }_{14}$ Schulz I, Stolze HH. The exocrine pancrease: the role of secretagogues, cyclic nucleotides and calcium in enzyme secretion. Ann Rev Physiol 1980;42:127-56.

is Selinger Z. Diverse functioning of calcium in the rat parotid acinar cell. In: Carafolie E. Calcium transport in contraction and secretion. Amsterdam: Elseviers/North Holland, 1975:139-46.

${ }^{16}$ Limbosch JM, Wyllie JH, Lloyd FT, et al. Initial observations on gastric physiology in the rabbit. Surg Forum 1966;17:311-3.

${ }^{17}$ Hirschowitz BI. Secretion of pepsinogen. In: Code CF, ed. Handbook of physiology. Alimentary Canal, section 6, vol II Washington DC: Am Physiol Soc, 1967:889-918.

${ }^{18}$ Kapadia CR, Donaldson RM. Macromolecular secretion by isolated gastric mucosa. Fundamental differences in pepsinogen and intrinsic factor secretion. Gastroenterology 1978;74:535-9.

${ }^{19}$ Karppanen AO, Neuvonen PJ, Bieck PR, Westerman E. Effect of histamine, pentagastrin and theophylline on the production of cyclic AMP in isolated gastric tissue of the guinea pig. Arch Pharmacol 1974;284:15-23.

${ }^{20}$ Dozois RR, Wollin A, Rettmann RD, Dousa IP. Effect of histamine on canine gastric mucosal adenylatecyclase. Am J Physiol 1977;E232:35-8.

${ }^{21}$ Ito M, Noguchi Y, Yokochi K, Kishimoto T, Tomomatsu T, Katsumi $K$, Takeuchi T. Effect of betazole hydrochloride and cyclic AMP on the pepsinogen secretion by rabbit gastric mucosa in organ culture. Digestion 1982;23:169-73.

${ }^{22}$ Hersey SJ, Owirodu A, Miller M. Forskolin stimulation of acid and pepsinogen secretion by gastric glands. Biochim Biophys Acta 1983;755:293-9.

${ }^{23}$ Johnson LR. Effect of gastric mucosal acidification on the action of pepsigogues. Am J Physiol 1973;225:1411-5.

Requests for reprints to: Dr J Défize, Institute of Human Genetics, Faculty of Medicine, Free University, PO Box 7161, 1007 MC Amsterdam, The Netherlands. 